\title{
Evaluation of Different Zirconia Surface Treatments on their Microhardness
}

Mohammed Riyadh Abdulateef BDS., (Master Student)

\section{Maan M. Nayif} BDS, MSc.PhD(Asst.Prof.)

\author{
Department of Conservative Dentistry \\ College of Dentistry, University of Mosul
}

Department of Conservative Dentistry College of Dentistry, University of Mosul

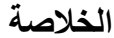

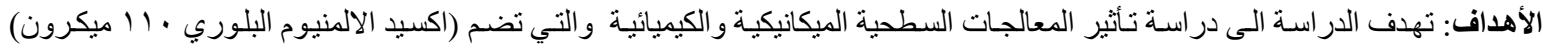

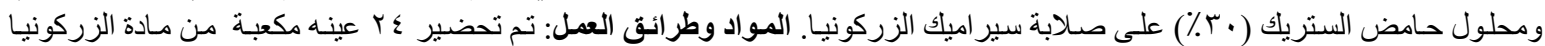

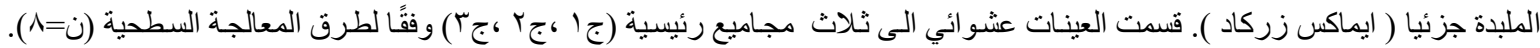

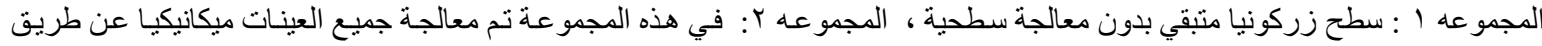

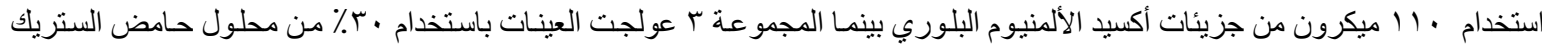

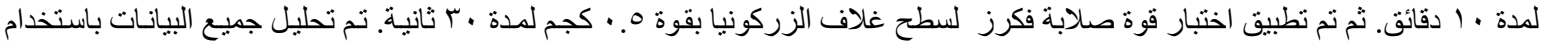

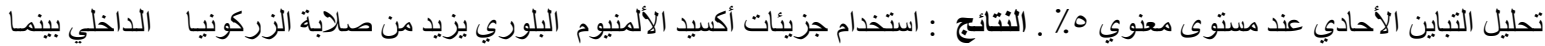

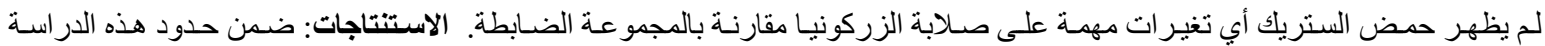
المختبرية ، يعمل العلاج الميكانيكي لسطح الزركونيا باستخدام جزيئات أكسيد الألمنيوم البلوري على تحسين صلابة سير اميك الزركونيا.
\end{abstract}

\begin{abstract}
Aims: To investigate the effect of mechanical and chemical surface treatments including $\left(\mathrm{AL}_{2} \mathrm{O}_{3}-110 \mu \mathrm{m}\right)$ and citric acid solution $(30 \%)$ on the microhardness of zirconia ceramic. Materials and Methods: Twenty four cubic shaped specimens were prepared from partial sintering zirconia (IPS e.max ZirCAD MT).Specimens were randomly assigned into three main groups (GI, GII, and GIII) according to the surface treatment methods $(n=8)$. Group I: zirconia surface left without surface treatment (control), Group II: In this group all specimens were subjected to sandblasting with $110 \mu \mathrm{m}$ Aluminum oxide particles (A12O3), while Group III: The surface was treated with citric acid solution $30 \%$ for 10 minutes. Force of Vickers microhardness was applied on the intaglio surface of the zirconia specimen at $0.5 \mathrm{~kg}$ for 30 seconds. Data

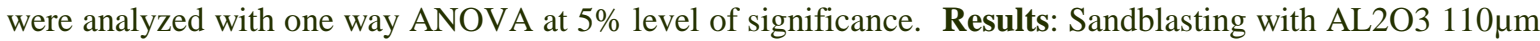
significantly increased the Vickers microhardness value of the zirconia surface. Chemical treatment with $30 \%$ citric acid did not exhibit any significant changes in comparison to the control group. Conclusions: Within the limitation of this in vitro study, the mechanical surface treatment of the zirconia surface with AL2O3 improves the surface microhardness.
\end{abstract}

Key words: Acid etching, Citric acid, Sandblasting, Surface treatment, Vickers hardness, Zirconia

Abdulateef MR., Nayif MM. Evaluation of Different Zirconia Surface Treatments on their Microhardness .Al-Rafidain Dent J. 2020 ;20 (1) 273-282.

DOI: 10.33899/rden.2020.166475 C2020, College of Dentistry, University of Mosul

Received: 27/6/2020 Sent to Referees: 30/6/2020 Accepted for Publication: 16/8/2020

This is an open access article under the CCBY4.0license (http://creativecommons.org/licenses/by/4.0/) 


\section{INTRODUCTION}

In the last decades, the increased requirements in esthetic dentistry have reached to the overcoming of the metalceramic prosthesis with a focus on nonmetal restorations. Zirconia restoration gains an effective role in dentistry due to its superior mechanical characteristics with good biocompatibility ${ }^{(1)}$. The mechanical behavior of zirconia restoration was documented to be better than other ceramics ${ }^{(2)}$. For example, the fracture toughness is double than aluminum oxide ceramics thus restoration fabricated from zirconia is expected to be more clinically durable ${ }^{(3,4)}$. Due to the resistance of the material to many treatments, the adhesion of zirconia to tooth substrate or luting material becomes difficult subject ${ }^{(5,6)}$. Different methods have been proposed to promote adequate adhesion between the resin cement and zirconia. Zirconia surface can be treated either by micromechanical process or by chemical modification of the surface or a combination of both ${ }^{(7)}$. The abrasion with aluminum oxide particles at different sizes ranged from $50-125 \mu \mathrm{m}$ is considered and proved as an efficient treatment of zirconia surface before their delivery ${ }^{(8)}$ A process involves attacking the surface with $\mathrm{AL}_{2} \mathrm{O}_{3}$ particles at different distance and pressure to create surface roughness and increase irregularity for better resin cement interlocking $(9,10)$. However, consideration of sandblasting effect on the mechanical properties and finally on the reliability of zirconia has been studied with some unfavorable outcome. This unfavorable effect may result from the phase transformation (tetragonal to monoclinic) by introducing flaws and reshaping the surface ${ }^{(11) .}$ To overcome sandblasting drawbacks another option has been tried with less destructive effect on the surface by using simple procedures to induce surface irregularity within zirconia through the application of strongly acidic solution ${ }^{(12)}$. Researchers have tried different chemical acid etching solutions including hydrofluoric acid because of its efficiency in ceramic etching. It is one of the most commonly used for silica-based ceramic with good results ${ }^{(13)}$. Such Acidic solution can't be really applied for glass-free zirconia. A substitute acidic solution for zirconia was invented by different studies ${ }^{(14)}$. A Recent study evaluated the citric acid solution of $30 \%$ applied for $10 \mathrm{~min}$. They claimed that surface roughness was possible with this type of acid and protocol 
Microhardness is a simple and reliable procedure to study the changes that occurs in surface resistance of the material. Many types of the microhardness test available depending on the mechanical properties of the tested material. Vickers hardness test can be applied for brittle substrates like zirconia ceramic. Little studies have considered changes in the prosthesis microhardness following sandblasted. Some studies showed an increase in the strength of zirconia after alumina particle abrasion (16, 17). According to our knowledge there are few studies available about microhardness of zirconia when surface treated with concentrated citric acid solution. The null hypothesis to be tested was that there is no difference in the microhardness values between different treatments (18). The study aimed to investigate the effect of different surface treatments on the Vickers microhardness of zirconia ceramic. It was hypothesized that different surface treatments wouldn't affect the microhardness of zirconia.

\section{MATERIALS AND METHODS}

\section{Specimen preparation:}

Twenty four specimens of cubic shaped $(10.0 \times 10.0 \times 2.0 \mathrm{~mm})$ as shown in Figure (1) were prepared from partial sintering zirconia IPS e.max ZirCAD MT disk (Ivoclar Vivadent; Schaan, Liechtenstein) using CAD/CAM system (Hint-ELs, Griesheim, Germany) and software data program. After the milling process was completed, the specimens were carefully separated from the zirconia blank disc by fine tungsten carbide burs. Margins of each specimen are adjusted with a football-shaped and fine fissure diamond burs to remove any excess.

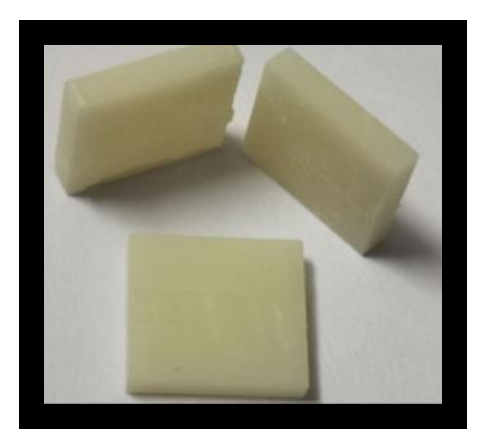

Figure (1): Zirconia specimens

Specimens were placed on the firing tray and insert into the furnace (Programat S1 1600, Ivocalar Vivadent, Schaan,
Liechtenstein) for complete sintering procedure. The sintering was performed for 2.5hours at $1500 \mathrm{C}^{\circ}$ as manufacturing 
instruction, with heating and cooling rates at $10{ }^{\circ} \mathrm{C} / \mathrm{min}$. The outer contour surface of the specimens was fine ground, polished, cleaned, dried, and finally a glaze firing. This procedure was similar to the clinically prepared prosthetic restoration, and to eliminate any evidence of flaws and defects on that surface (18). Specimens were ultrasonically cleaned for 15 minutes using Ultrasonic Cleaner (Shenzhen Langee Ultrasonic Electric Co., China).

\section{Surface treatment methods:}

Specimens were randomly divided equally into three groups (GI, GII, and GIII) according to the surface treatment methods $(n=8)$. Group (I): The zirconia surface received no surface treatment which served as a control group. Group (II): In this group, all specimens were subjected to Sandblasting treatment as follows. Specimens were held in a metallic tool at a distance of $10 \mathrm{~mm}$ between specimen surface and blasting tip. The intaglio surfaces were sandblasted with 110 $\mu \mathrm{m}$ Aluminum oxide particles $\left(\mathrm{Al}_{2} \mathrm{O}_{3}\right){ }^{(19)}$, using an airborne particle-abrasive device (Rotaks Dent Dişcilik San Ve Tuc Ltd., İstanbul, Turkey). The sandblasting pen with the tip nozzle size of $3 \mathrm{~mm}$ was used in rotational movements and the operational pressure was constant (2.5 bar) for $15 \mathrm{~s}$ (20). Group (III): The specimens of this group were subjected to chemical treatment. The intaglio surface of Zirconia plates was treated with citric acid solution $30 \%$ for 10 minutes by using micro-brush for solution application. Then the specimens were gently washed with distilled water for one minute and dried.

\section{Microhardness test:}

Zirconia specimen was fixed on the microhardness stage in perpendicular alignment to the indentation head. The diamond pyramid head of Vickers microhardness testing machine (Amsler Otto Wolpert-Werke GmbH-Ludwigshafen Germany) was applied to the intaglio surface of zirconia specimen at a force of $0.5 \mathrm{~kg}$ for 30 seconds as shown in Figure (2). The length of the two indentation lines was measured at $40 \times$ through the built-in scale microscope as shown in Figure (3). The measurements were converted into a micro-hardness value (VHN) using the following equation: $\mathrm{HV}=1.854$ $\mathrm{P} / \mathrm{d}^{2},(\mathrm{P}=$ applied load in $\mathrm{kg}), \mathrm{d}=$ indentations diagonal length in $\mathrm{mm})^{(21)}$.Three indentation were applied for each specimen at three different locations (left, right, and central regions).Values were averaged and reported as a single value. The data were statistically analyzed using one way ANOVA test and Duncan's Multiple Range Test for post hoc comparison. All the analysis was performed at $5 \%$ level of significance. 


\section{Hardness of zirconia following surface treatments}

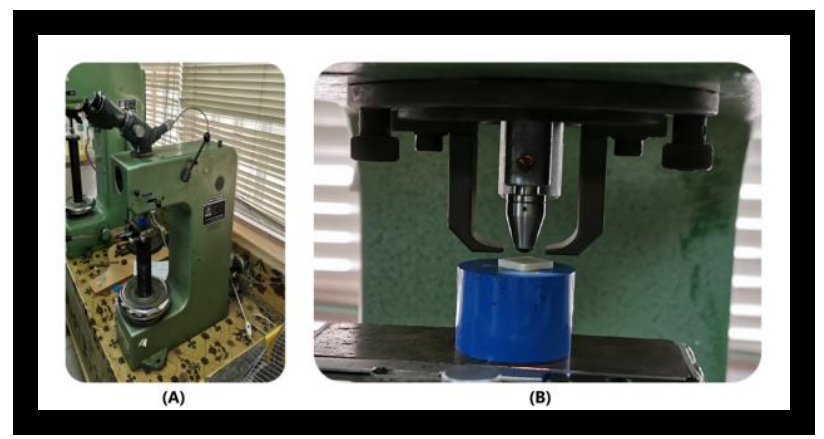

Figure (2): A: Vickers microhardness testing machine. B: Diamond pyramid head of Vickers microhardness tester applied on the intaglio surface of zirconia specimen

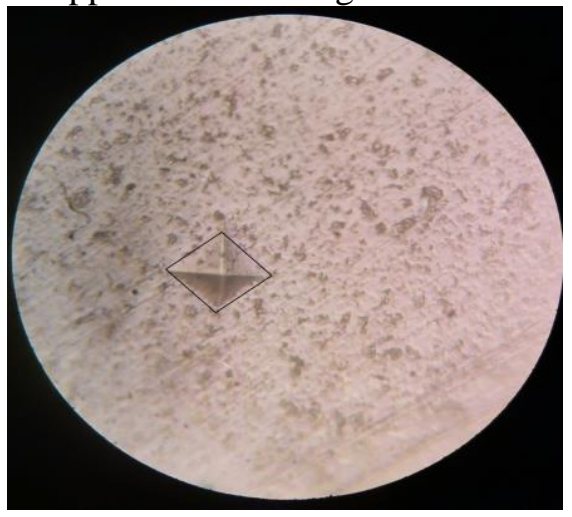

Figure (3): Microscopic image of Vickers indentation on the surface of zirconia.

\section{RESULTS}

Descriptive statistic including the mean and standard deviation (SD) of microhardness values following different treatments were shown in Table(1). The highest microhardness value was observed in specimen treated with sandblasting however the other treatments show almost similar values.

Table (1): Mean and SD of zirconia microhardness.

\begin{tabular}{ccc}
\hline Treatment techniques & Mean $\mathbf{K} \mathbf{g}_{\mathbf{f}} / \mathbf{m m}^{\mathbf{2}}$ & Std. Deviation \\
\hline Control (No surface treatment) & 1876.17 & 173.91 \\
Sandblasting $\left(\mathbf{A L}_{\mathbf{2}} \mathbf{O}_{\mathbf{3}} \mathbf{1 1 0} \boldsymbol{\mu m}\right)$ & 2202.78 & 157.27 \\
Citric acid $30 \%$ & 1836.98 & 170.48 \\
\hline
\end{tabular}

One-way ANOVA revealed a significant difference in the microhardness values among different treatments $(p<0.05)$ as shown in Table (2) 
Table (2): One way (ANOVA) showed the effect of different treatments on the microhardness of zirconia.

\begin{tabular}{cccccc}
\hline $\begin{array}{c}\text { Treatments } \\
\text { technique }\end{array}$ & $\begin{array}{c}\text { Sum of } \\
\text { Squares }\end{array}$ & Df & $\begin{array}{c}\text { Mean } \\
\text { Square }\end{array}$ & F & Sig. \\
\hline $\begin{array}{c}\text { Between } \\
\text { Groups }\end{array}$ & 1210049.66 & 2 & 605024.83 & 21.60 & $.000^{* *}$ \\
$\begin{array}{c}\text { Within } \\
\text { Groups }\end{array}$ & 1176538.80 & 42 & 28012.83 & & \\
Total & 2386588.47 & 44 & & & \\
\hline
\end{tabular}

** Highly significance at $(\mathrm{p}<0.01)$

Duncan's New Multiple Range Test showed that the sandblasted zirconia surface has significantly higher microhardness value than control and citric acid-treated groups $(p<0.05)$. While there was no significant difference between the citric acid group and the control group (no surface treatment) $(p>0.05)$ as shown in Figure (4).

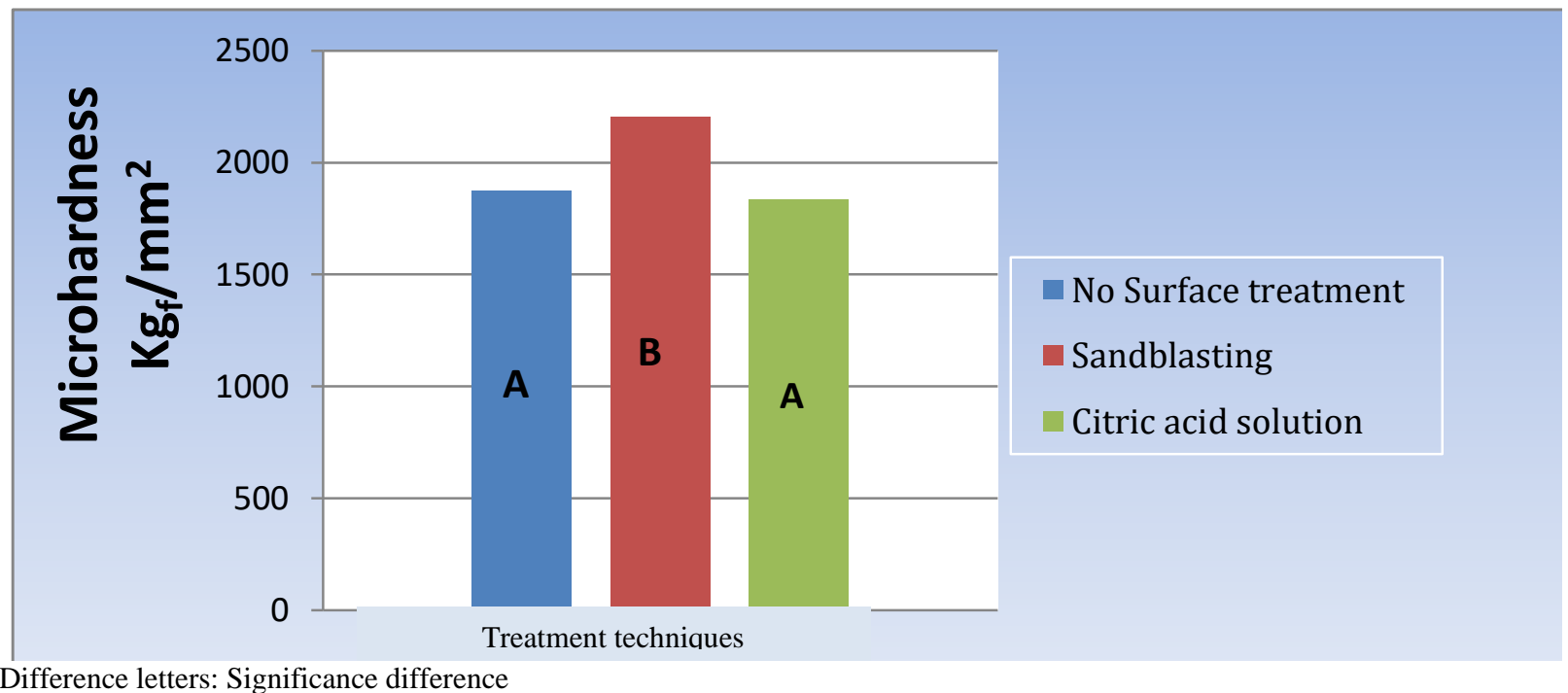

Difference letters: Significance difference

Figure (4): Column graph for Duncan's Multiple Range Test showed the effect of different surface treatments on the microhardness of IPS e.max ZirCAD.

\section{DISCUSSION}

Surface hardness is one of the paramount physical property that affects the clinical performance of zirconia restorations. It contributes to resistance of the material to the external force (22). Zirconia-based dental restorations are subjected to continuous loads with contacts during functional chewing and mastication therefore; the mechanical properties such as hardness influence the long-term performance of the restorations ${ }^{(23)}$. In this study, microhardness property was investigated after mechanical sandblasting of zirconia restorations with $\left(\mathrm{AL}_{2} \mathrm{O}_{3} 110 \mu \mathrm{m}\right)$ and 
chemical etching with citric acids as a technique to create irregularities within zirconia surface before fixation for better luting. The result demonstrates a difference between the different treatments thus the null hypothesis that proposed that there was no difference between the treatments was rejected. The treatment of zirconia surface with $\mathrm{AL}_{2} \mathrm{O}_{3} 110 \mu \mathrm{m}$ increased the resistance of the zirconia surface to the applied force from the microhardness testing device. This result may be of benefit particularly when a change in structure of the zirconia is limited without transformation. In this regard, Chintapalli et $a l^{(24)}$ have evaluated this feature following mechanical treatment and concluded that sandblasting with $110 \mu \mathrm{m}$ could be beneficial since it induces limited damage to the surface of zirconia surface compared to with larger particles. However, sandblasting is still has the ability to induce phase transformation of surface crystals without developing high temperatures or creating severe surface damage, and therefore, strengthening the material ${ }^{(24,25,26)}$. Several studies reported an increase in strength after sandblasting as compared to other treatment techniques and related such finding to increase in tetragonal to a monolithic transformation of the surface crystals with an associated increase in strength $(5,27)$. Another reason that may participate in the increase in the value of surface microhardness is the precipitation of the $\mathrm{Al}_{2} \mathrm{O}_{3}$ particles within the abraded surface.
Microhardness test measures the resistance of the surface to the applied indentation. The particles size used in this study was relatively large $110 \mu \mathrm{m}$ with quality could provide good strength and stiffness. Diamond indenter may probably hit such particles embedded within the abraded surface during the testing procedure thus influencing the measurement process by adding extra resistance force with elevated outcome value ${ }^{(28)}$. Zirconia ceramic has a polycrystalline structure, which is chemically inert and may exhibit a potential resistance to aggressive chemical agents such as (strong acid, alkalis, organic, and inorganic dissolving agents). A zirconia has property dissimilar to ceramic because zirconia is a glass-free material ${ }^{(16)}$ In this study when the surface of the zirconia exposed to $30 \%$ of citric acid for $10 \mathrm{~min}$ and evaluated in response to external force represented by microhardness test, the result shows no difference from the untreated surface. Xie et al ${ }^{(29)}$ showed that when zirconia specimens immersed in $20 \%$ of citric acid solution at ambient temperature, there were no significant changes in mechanical properties including two parameters flexural strength, and Vickers microhardness. In addition, other study investigated other chemical agents and reported that zirconia was resistant to other acidic solution like acetic acid reflux without compromising it strength (30). This result confirms that surface treatment with $30 \%$ citric acid does not induce any alteration in 
terms of surface microhardness. Other surface changes rather than microhardness may be expected after citric acid treatment. A study by Hasan et al $(15,18)$ demonstrated topographical alteration within surface exposed to citric acid when examined under SEM. Further study may be necessary to confirm this alteration.

\section{CONCLUSIONS}

Within the limitation of this study mechanical surface treatment of zirconia via sandblasting with $\mathrm{AL}_{2} \mathrm{O}_{3}(110 \mu \mathrm{m})$ has increased the microhardness of zirconia meanwhile treatment with $30 \%$ of citric acid solution applied for $10 \mathrm{~min}$ has no effect on the microhardness.

\section{REFERENCES}

1. Al-Amleh B, Lyons $\mathrm{K}$, Swain $\mathrm{M}$. Clinical trials in zirconia: a systematic review.J Oral Rehabil. 2010; 37(8):641-652.

2. Ali SA, Karthigeyan S, Deivanai M., Ma R. Zirconia: Properties and application - A review. Pak Oral Dent J. 2014; 34(1):178-183.

3. Triwatana P, Nagaviroj N, Tulapornchai C. Clinical performance and failures of zirconia-based fixed partial dentures: a review of literature. $J$ Adv Prosthodont. 2012; 4(2): 76-83.

4. Sailer I, Feher A, Filser F, Gauckler LJ, Lüthy $\mathrm{H}$, Hämmerle $\mathrm{CH}$. Five-year clinical results of zirconia frameworks for posterior fixed partial dentures. Int $J$ Prosthodont. 2007; 20(4): 383-388.

5. Aboushelib M, Feilzer A J, \& Kleverlaan CJ. Bonding to Zirconia Using a New Surface Treatment. $J$ Prosthodont. 2010; 19(5), 340-346.

6. Mattiello R, Coelho T, Insaurralde E, Coelho A, Terra G, Kasuya A, Favarão I, Gonçalves L, \& Fonseca R. A Review of Surface Treatment Methods to Improve the Adhesive Cementation of Zirconia-Based Ceramics. ISRN Biomaterials. 2013.

7. Melo RM, Souza R, Dursun E, Monteiro E, Valandro LF, \& Bottino MA Surface treatments of zirconia to enhance bonding durability. Oper. Dent. 2015; 40(6) 636-643.

8. Grasel R, Santos M, Rêgo HC, Rippe M., \& Valandro L. Effect of Resin Luting Systems and Alumina Particle Air Abrasion on Bond Strength to Zirconia. Oper Dent. 2018; 43(3), 282 290.

9. Tzanakakis EG, Tzoutzas IG, Koidis PT. Is there a potential for durable adhesion to zirconia restorations? A systematic review. J Prosthet Dent. 2016; 115(1):9-19.

10. Yenisey M, Dede DO, and Rona N. Effect of surface treatments on the bond strength between resin cement and differently sintered zirconium-oxide 
ceramics. J Prosthodont Res. 2016; 60(1): 36-46.

11. Su N, Yue L, Liao Y, Liu W, Zhang H, Li X, Wang H, \& Shen J. The effect of various sandblasting conditions on surface changes of dental zirconia and shear bond strength between zirconia core and indirect composite resin. $J$ Adv Prosthodont. 2015; 7(3):214-223.

12. Liu D, Tsoi J, Matinlinna J, \& Wong HM. Effects of some chemical surface modifications on resin zirconia adhesion. J Mech Behav Biomed Mater.2015; 46, 23-30.

13. Bajraktarova-Valjakova E, Grozdanov A, Guguvcevski L, KorunoskaStevkovska V, Kapusevska B, Gigovski N, Mijoska A, Bajraktarova-Misevska C. Acid Etching as Surface Treatment Method for Luting of Glass-Ceramic Restorations, part 1: Acids, Application Protocol and Etching Effectiveness. Open Access Maced J Med Sci. 2018; 6(3):568-573.

14. Bottino MA, Bergoli C, Lima EG, Marocho SM, Souza RO, Valandro LF. Bonding of Y-TZP to dentin: effects of Y-TZP surface conditioning, resin cement type, and aging. Oper Dent. 2014; 39(3):291-300.

15. Hasan $\mathbf{N H}$, Nayif $\mathbf{M}$, and Taqa $A$. Adhesion to Zirconia Restorations a Problem Can Be Solved .IJERMDC. 2019; 6(6): 28-38.
16. Wang H, Aboushelib MN, Feilzer AJ. Strength influencing variables on CAD/CAM zirconia frameworks. Dent Mater. 2008; 24(5):633-638.

17. Liu Q, Shao LQ, Hu C, Deng B, Yi Y F, \& Wen N. Mechanical Properties of Y-TZP Ceramic after Different Surface Treatments. Key Eng Mater. 2011; 492, 71-74.

18. Hasan NH, Nayif M, and Taqa A. Effect of hydrogen peroxide and citric acid on surface conditioning of different types of zirconia based restoration that are associated with resin cement. Thesis. Mosul University, Dentistry College. Mosul, Iraq. 2019.

19. Gomes AL, Castillo-Oyagüe R, Lynch $\mathrm{CD}$, Montero J, Albaladejo A .Influence of sandblasting granulometry and resin cement composition on microtensile bond strength to zirconia ceramic for dental prosthetic frameworks. J Dent. 2013; 41(1):31-41.

20. Yang, B., Barloi, A., and Kern, M. Influence of air-abrasion on zirconia ceramic bonding using an adhesive composite resin. Dent Mater. 2010; 26(1):44-50

21. El Gamal A, Rocca JP, Fornaini C, Medioni E, Brulat-Bouchard N. Microhardness evaluations of CAD/CAM ceramics irradiated with $\mathrm{CO}_{2}$ or $\mathrm{Nd}$ :YAP laser. Laser Ther. 2017; 26(1):13-18. 
22. Shao L, Jiang D, \& Gong J. Nanoindentation Characterization of the Hardness of Zirconia Dental Ceramics. Adv Eng Mater. 2013; 15(8), 704-707.

23. Chintapalli RK, Mestra Rodriguez A, Garcia Marro F, Anglada M. Effect of sandblasting and residual stress on strength of zirconia for restorative dentistry applications. J Mech Behav Biomed Mater. 2014; 29(1):126-137.

24. Chintapalli RK, Marro FG, JimenezPique E, \& AngladaM. Phase transformation and subsurface damage in 3Y-TZP after sandblasting. Dent Mater. 2013; 29(5):566-572.

25. Karakoca S, Yilmaz H. Influence of surface treatments on surface roughness, phase transformation, and biaxial flexural strength of Y-TZP ceramics. J Biomed Mater Res B Appl Biomater. 2009; 91(2):930-937

26. Curtis AR, Wright AJ, Fleming GJ. The influence of surface modification techniques on the performance of a $\mathrm{Y}$ TZP dental ceramic. J Dent. 2006; 34(3):195-206.

27. Kosmač T, Oblak C, and Marion L. The Effects of Dental Grinding and Sandblasting on Ageing and Fatigue Behavior of Dental Zirconia (Y-TZP) Ceramics. J Eur Ceram Soc. 2008; 28(5):1085-1090

28. Śmielak B, Klimek L. Effect of Air Abrasion on the Number of Particles Embedded in Zironia. Materials (Basel). 2018; 11(2):259-271.

29. Xie H, Shen S, Qian M, Zhang F, Chen C, Tay FR. Effects of Acid Treatment on Dental Zirconia: An In Vitro Study. PLoS One. 2015; 10 (8):e0136263.

30. Ardlin BI. Transformation-toughened zirconia for dental inlays, crowns and bridges: chemical stability and effect of low-temperature aging on flexural strength and surface structure. Dent Mater. 2002; 18(8):590-595. 